\title{
Formulation of Non-effervescent Floating Dosage Form of Metronidazole using Sintering and Sublimation Technique
}

\author{
Airemwen Collins Ovenseri and Uhumwangho Uwumagbe Michael \\ Department of Pharmaceutics and Pharmaceutical Technology, Faculty of Pharmacy \\ University of Benin, Nigeria
}

(Received: September 10, 2019; Accepted: December 10, 2020; Published (web): January 02, 2021)

\begin{abstract}
The aim of this study was to formulate a novel non-effervescent floating dosage form of metronidazole using the sublimation and sintering technique. Granules were formulated using the wet granulation technique. Ammonium bicarbonate $(30 \% \mathrm{w} / \mathrm{w})$ was incorporated as the sublimating agent. The granules were characterized for micromeritic properties. Thereafter, the granules were compressed using a single punch tableting machine and the physicotechnical properties were evaluated. The metronidazole tablet was then sintered at $70^{\circ} \mathrm{C}$ for $12 \mathrm{~h}$. All granules were free flowing and compressible. The metronidazole tablets had no floating lag time showing that tablets floated instantaneously. FTIR and DSC studies showed that metronidazole and the excipients used in the formulation were compatible. Azadirachta indica gum was used in the formulation of non-effervescent floating dosage form of metronidazole using sublimation and sintering technique which is beneficial in sustained release formulations.
\end{abstract}

Key words: Azadirachta indica, floating, gastroretention, metronidazole, non-effervescent.

\section{INTRODUCTION}

Floating dosage forms are preparations that have a bulk density that is less than that of gastric fluids, hence remain floating in the stomach for a long period of time without altering the rate of gastric emptying. While the dosage form is floating on the gastric fluid, the drug is released slowly at a steady rate from the dosage form ${ }^{1}$. This leads to an increase in the gastroretention time and a good control of variations in the concentration of the drug in the plasma. $^{2}$

Floating dosage forms can be formulated using effervescent and non-effervescent techniques. Effervescent technique involves the use of gas generating agents such as sodium bicarbonate and organic acids such as citric acid and

Correspondence to: Collins O. Airemwen

Phone no. : +2348133737933

Email: collins.airemwen@uniben.edu

Dhaka Univ. J. Pharm. Sci. 20(1): 11-17, 2021 (June)

DOI: https://doi.org/10.3329/dujps.v20i1.50853 tartaric acid to generate carbon (iv) oxide $\left(\mathrm{CO}_{2}\right)$ gas. $\mathrm{CO}_{2}$ can be generated in situ by incorporation of bicarbonates or carbonates, which react with either the natural gastric acid in the stomach or tartaric acid co-formulated in the dosage form. This imparts buoyancy on the dosage form, thereby decreasing the bulk density of the dosage form and enabling it to float on top of the gastric fluid. ${ }^{3}$ These effervescent floating dosage forms can further be classified into two types: (i) Gas generating drug delivery systems which include intragastric single layer floating tablets, intragastric bilayer floating tablets and multiple unit type floating tablets; (ii) Liquid/vacuum containing systems which include inflatable gastrointestinal delivery systems and intragastric osmotically controlled drug delivery system while the non-effervescent technique involves the use of highly swellable cellulose type hydrocolloids, gel-forming hydrocolloids or matrix forming polymers such as polyacrylate, polystyrene and polycarbonate. In this approach, gel forming hydrocolloid swells when it 
comes in contact with gastric fluid after oral administration and maintains a specific shape and a bulk density lower than that of the gastric fluid. ${ }^{4}$ The air trapped by the swollen polymer is thus responsible for the buoyancy of the dosage form, examples of these systems include: hydrodynamically balanced system, microbaloons or hollow microspheres, sintering and sublimation system, alginate beads and microporous compartment.

Metronidazole is antiprotozoal medication that is used in the management of pelvic inflammatory disease, bacterial vaginosis, trichomoniasis, giardiasis and amebiasis. ${ }^{5}$

Azadirachta indica is a fast growing evergreen tree found commonly in Africa, India and America. It has been used in ayurvedic medicine over the years due to its therapeutic properties. It is commonly called 'Indian llilac'or 'Dongoyaro' and belongs to the family Meliaceae. It possesses anti-allergenic, anti-fungal, anti-inflammatory, diuretic, larvicidal, anti-scabic and other biological activities. ${ }^{6}$

The binding and mechanical properties of the gum have been previously studied by many researchers. ${ }^{6}$ However, its binding properties in the formulation of non-effervescent floating dosage form has not been studied.

The purpose of this research was to formulate a non-effervescent floating dosage form of metronidazole using the sintering and sublimation technique and Azadirachta indica gum as a binder. This technique offers zero floating lag time as compared to the effervescent method. Floating of the tablets on top of the gastric fluid is the rate-limiting and very important step in the release of the active ingredients from the dosage form hence; this technique eliminates the barrier to the efficient release of drugs from the dosage form associated with the effervescent technique where there is always floating lag time or sometimes failure to float. ${ }^{4}$

\section{MATERIALS AND METHODS}

Metronidazole obtained from Ranbaxy, India was used in this study as the active ingredient and acrylate methacrylate copolymer (Eudragit ${ }^{\circledR}$ RL100) was purchased from Rhoma Pharmaceuticals,
Frankfurt, Germany. Azadirachta indica gum was used as a binder and was extracted by method described previously described by Abayomi and Gbenga $^{6}$ with some slight modifications. Ammonium bicarbonate was obtained from Cipla Pharma (India) and was used as the sublimating agent. The other chemicals were of analytical grade.

Preparation and determination of the micromeritic properties of granules. The metronidazole granules were formulated using the wet granulation method. Four batches were prepared using Azadirachta indica gum at varying concentrations $(2,4,6$ and $8 \% \mathrm{w} / \mathrm{w})$ with $1 \% \mathrm{w} / \mathrm{w}$ of Eudragit ${ }^{\circledR}$ RL100. One extra batch was also prepared without the addition of Eudragit ${ }^{\circledR}$ RL100 at $2 \%$ w/w concentration.

In each formulation, the lactose, ammonium carbonate and metronidazole were mixed in the dry state in a mortar using the geometric mixing method. Then the binder mixtures of the gum and Eudragit ${ }^{\circledR}$ RL100 were used to wet mass the powder in the mortar. The damp mass formed was forced through a sieve mesh of $850 \mu \mathrm{m}$ and dried at $60^{\circ} \mathrm{C}$ for $30 \mathrm{~min}$. It was then sieved using a sieve mesh of $710 \mu \mathrm{m}$. The flow and compressibility properties were determined by measuring the angle of repose, bulk density, tapped density and Carr's Index $^{7}$ using standard procedures. $^{8}$

Formulation of floating metronidazole tablets. The composition of the formulation of floating matrix tablet of metronidazole is shown in Table 1. A single punch tableting machine (Type F3 Manesty Machine, UK) was used to formulate the tablets. The granules equivalent to $400 \mathrm{mg}$ of metronidazole were placed in the die of the tableting machine and compressed into tablets at a compression pressure of $35 \mathrm{~N} / \mathrm{m}^{2}$. A constant pressure was used in the formulation of all the batches of metronidazole. The formulated tablets were then sintered (heated) in a hot-air oven at $70^{\circ} \mathrm{C}$ for $12 \mathrm{~h}$ and this resulted in the sublimation of the ammonium carbonate thereby creating pores in the tablets. 
Table 1. The formula for non-effervescent floating metronidazole tablets.

\begin{tabular}{lll}
\hline S/N & Ingredients & Quantity \\
\hline 1 & Metronidazole powder & $400 \mathrm{mg}$ \\
2 & Azadirachta indica gum & $2,4,6,8 \% \mathrm{w} / \mathrm{w}$ \\
3 & Eudragit RL100 & $1 \%$ \\
4 & Ammonium carbonate & $30 \%$ \\
5 & Talc & $1 \%$ \\
6 & Lactose & Qs \\
\hline
\end{tabular}

\section{Evaluation of metronidazole tablets}

Tablet hardness and friability. The hardness test was done on four (4) randomly selected tablets using Electronics Hardness tester machine. The mean and standard error of mean values were recorded. The friability test was done on five (5) tablets a Roche Friabilator.

Floating lag time (FLT) and in vitro buoyancy test. The method described previously by Rosa et al. was adopted. ${ }^{9}$ A $1000 \mathrm{ml}$ beaker was filled with 900 $\mathrm{ml}$ simulated gastric fluid $(0.1 \mathrm{~N} \mathrm{HCl})$. A tablet was immersed and the medium was maintained at $37 \pm$ $2^{\circ} \mathrm{C}$. The time taken for the tablet to rise to the surface and float was recorded as the FLT. The time duration for which the tablet floats and remained afloat without fracturing was recorded as the as in vitro buoyancy time.

In vitro dissolution studies and drug release kinetics. The paddle method was used and dissolution studies were done using standard method previously described by Airemwen and Uhumwangho. ${ }^{1}$ The data recorded from the dissolution studies were subjected to zero, first order and Higuchi release models. ${ }^{10}$ Korsemeyer and Peppas model was used to determine the mechanism of drug release from the formulation. ${ }^{11,12}$

Compatibility studies. Compatibility studies were carried out using Fourier transform infra-red
(FTIR) spectrophotometer and differential scanning calorimetry (DSC) and the spectra of the pure drug (active ingredient), physical mixture of metronidazole, neem gum plus other ingredients and the optimized tablet formulation containing $6 \% \mathrm{w} / \mathrm{w}$ neem gum were studied.

Scanning electron microscopy (SEM). SEM was done on the tablets samples using scanning electron microscope (Munich, Germany).

Statistical analysis. The data obtained were recorded as mean \pm standard error of mean (SEM). All the data were analyzed using Graphpad Instat. P $<0.05$ was considered to be significant.

\section{RESULTS AND DISCUSSION}

The micromeritic properties of the floating metronidazole granules formulated by varying concentrations of $A$. indica gum (AIG) are shown in table 2. All the granules formulated with AIG had angle of repose values ranging from $28-35^{\circ}$ while Carr's indices ranged from $11-16 \%$. The Hausner's ratio was between $1.12-1.20$. These results show that all the floating matrix granules displayed good flow properties which is very important in ensuring weight and content uniformities during tableting.

The hardness of the various batches (A1-A5) of formulated floating metronidazole tablets ranged from $4.5 \pm 0.1$ to $8.2 \pm 0.1 \mathrm{Kpa}$ indicating good mechanical strength with an ability to withstand physical and mechanical stress during shipping, packaging, storage and transportation. The friability values ranged from $0.91 \pm 0.01$ to $0.95 \pm 0.02 \%$. The value was less than $1 \%$ which conforms to the $\mathrm{BP}$ specification ${ }^{13}$ (Table 3 ).

Table 2. Flow and packing properties of the non-effervescent granules of metronidazole formulated with $A$. indica gum.

\begin{tabular}{|c|c|c|c|c|c|c|}
\hline $\begin{array}{l}\text { A. } \\
\text { Eudragit }{ }^{\circledR} \mathrm{RL}_{100} \\
(\% \mathrm{w} / \mathrm{w})\end{array}$ & indica: & $\begin{array}{l}\text { Bulk density } \\
\left(\mathrm{g} / \mathrm{cm}^{3}\right)\end{array}$ & $\begin{array}{l}\text { Tap density } \\
\left(\mathrm{g} / \mathrm{cm}^{3}\right)\end{array}$ & $\begin{array}{c}\text { Angle of repose } \\
\left({ }^{\circ} \mathrm{C}\right)\end{array}$ & $\begin{array}{l}\text { Carr's index } \\
(\%)\end{array}$ & $\begin{array}{c}\text { Hausner's } \\
\text { Ratio }\end{array}$ \\
\hline A1 & & $0.55 \pm 0.03$ & $0.62 \pm 0.02$ & $28.0 \pm 1.1$ & $11.3 \pm 1.0$ & $1.13 \pm 0.02$ \\
\hline A2 & & $0.57 \pm 0.02$ & $0.64 \pm 0.03$ & $30.1 \pm 1.1$ & $11.0 \pm 1.2$ & $1.12 \pm 0.01$ \\
\hline A3 & & $0.51 \pm 0.03$ & $0.61 \pm 0.01$ & $31.3 \pm 1.0$ & $15.9 \pm 1.3$ & $1.20 \pm 0.01$ \\
\hline A4 & & $0.49 \pm 0.01$ & $0.57 \pm 0.03$ & $34.0 \pm 1.0$ & $14.0 \pm 1.2$ & $1.16 \pm 0.01$ \\
\hline A5 & & $0.48 \pm 0.02$ & $0.57 \pm 0.02$ & $35.0 \pm 1.1$ & $15.8 \pm 1.0$ & $1.19 \pm 0.01$ \\
\hline
\end{tabular}

Where; A1 (AIG alone), A2 (2\%w/w neem gum: 1\%w/w Eudragit), A3 (4\%w/w neem gum: 1\%w/w Eudragit), A4 (6\%w/w neem gum: 1\%w/w Eudragit), A5 (8\%w/w neem gum: 1\%w/w Eudragit). 
Table 3. Hardness and friability results of the non-effervescent metronidazole tablets $(n=3)$.

\begin{tabular}{lcc}
\hline $\begin{array}{l}\text { A. indica }: \text { Eudragi }{ }^{\circledast} \mathrm{RL}_{100} \\
\text { Formulation }(\% \mathrm{w} / \mathrm{w})\end{array}$ & $\begin{array}{c}\text { Hardness } \\
\left(\mathrm{kg} / \mathrm{cm}^{2}\right)\end{array}$ & $\begin{array}{c}\text { Friability } \\
(\%)\end{array}$ \\
\hline A1 & $4.5 \pm 0.10$ & $0.95 \pm 0.01$ \\
$\mathrm{~A} 2$ & $5.5 \pm 0.11$ & $0.95 \pm 0.02$ \\
$\mathrm{~A} 3$ & $7.4 \pm 0.13$ & $0.93 \pm 0.01$ \\
$\mathrm{~A} 4$ & $8.1 \pm 0.12$ & $0.91 \pm 0.02$ \\
$\mathrm{~A} 5$ & $8.2 \pm 0.11$ & $0.91 \pm 0.01$ \\
\hline
\end{tabular}

Table 4 shows the result of the in vitro buoyancy study. All the tablet formulations had zero floating lag time $(0 \mathrm{~s})$ as they floated instantaneously when immersed on the simulated gastric fluid $(0.1 \mathrm{~N} \mathrm{HCl})$. The mechanism of floating was as a result of the sublimation of the ammonium carbonate from the tablets during the sintering (heating) process thereby creating pores in the tablets which enable the tablets to float freely on top of the simulated gastric fluid. The sublimation of the ammonium carbonate also reduces the bulk density of the tablets less than that of the simulated gastric fluid thus conferring buoyancy. ${ }^{14}$

Batch A1 (2\%w/w neem gum without Eudragit ${ }^{\circledR}$ RL100) showed buoyancy duration without rupture of $30 \mathrm{~min}$ while batches A2-A5 had buoyancy duration of 8-12 h. However, the floating time of AIG1 was relatively short as the tablets eroded during the test because the simulated dissolution medium gradually penetrated into the tablets, resulting in its disintegration. ${ }^{15}$ This was due to the fact that Eudragit ${ }^{\circledR}$ RL100 was not incorporated in batch $\mathrm{A} 1$ as it helps to maintain the integrity of the tablets thereby imparting more buoyancy time for the tablets formulations. ${ }^{16}$ The addition of Eudragit ${ }^{\circledR}$ RL100 helped to increase the integrity of the tablet and imparted more buoyancy time for the tablets formulations (A2-A5) and also sustained the drug release. $^{3}$

Table 4. Floating lag time and in vitro buoyancy values of non-effervescent metronidazole tablets formulated using AIG.

\begin{tabular}{|c|c|c|c|c|c|}
\hline Formulation concentration of AIG: Eudragit ${ }^{\circledR}{ }^{R L}{ }_{100}$ & A1 & A2 & A3 & A4 & A5 \\
\hline Floating lag time (s) & 0 & 0 & 0 & 0 & 0 \\
\hline Buoyancy time without rupture of tablet (h) & 0.5 & 8 & 10 & 11 & 12 \\
\hline
\end{tabular}

\section{Release profile of the floating metronidazole} tablets. The in vitro drug release profiles of the floating metronidazole tablets formulated using AI gum are shown in figure 1 . The drug release from the floating metronidazole tablet of $2 \% \mathrm{w} / \mathrm{w}$ A. indica gum without Eudragit ${ }^{\circledR}$ RL100 (batch AIG1) showed a faster release of drug content compared to the other batches (A2-A5) containing Eudragit ${ }^{\circledR}$ RL100. This is because Eudragit ${ }^{\circledR}$ RL100 helps in maintaining the integrity of the tablet and sustaining the drug release from the tablet formulations. It was also observed that there was a decrease in the rate of release of the drug content as the concentration of the gum increased. ${ }^{5}$ Batch A1 tablets displayed a faster release of drug content compared to the other batches containing Eudragit ${ }^{\circledR}$ RL100. There was a more sustained release of drugs from batches A2 - A5. This shows that the release profile of the tablet was concentration dependent. The higher the concentration of the gum, the more sustained the release of drug content from the matrix of the tablet. ${ }^{17}$ This perhaps may be due to low permeability which acts as a rate controlling factor in retarding of drug release from matrix systems. It was also observed that the time to attain maximum release in the floating tablets also reduced as the concentration of the gum increased. ${ }^{18}$ Drug release from the matrix tablet resulted from slow diffusion of dissolved drug molecules through aqueous filled channel in the polymeric matrix network. ${ }^{19}$ Table 5 shows the 
dissolution. The higher the concentration of the gums, the more retarded the drug release from the tablets. This reveals that the drug release from the floating metronidazole tablets is dependent on the concentration of the gum. It was also observed that there was a significant prolongation in the rate of drug release from the floating metronidazole tablets as amount of the gum increased. ${ }^{20}$

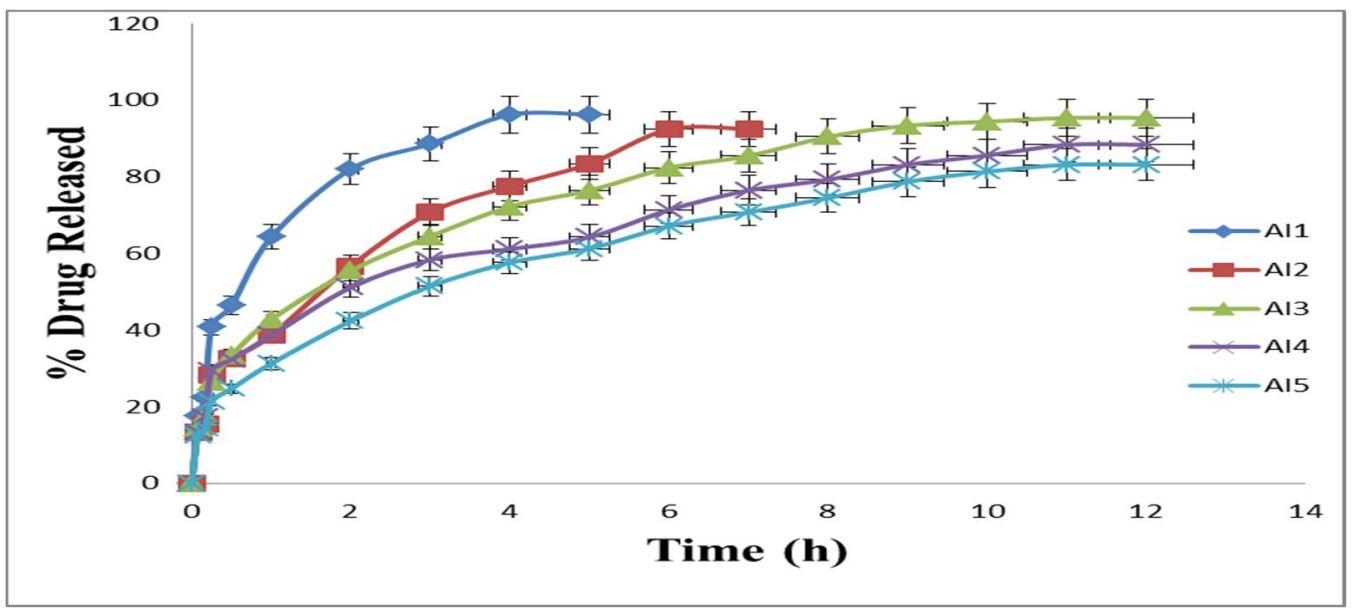

Figure 1. Drug release profiles of FMTs of metronidazole prepared with varying concentrations of AIG.

Table 5. Dissolution parameters of non-effervescent floating matrix tablets of metronidazole $\left(\mathbf{m}_{\infty} \%\right),\left(t_{\infty} h r\right),\left(\mathbf{m}_{\infty} / t_{\infty}\right)$

\begin{tabular}{llll}
\hline $\begin{array}{l}\text { AIG: Eudragit }{ }^{\circledR} \mathrm{RL}_{100} \\
(\% \mathrm{w} / \mathrm{w})\end{array}$ & $\mathrm{m}_{\infty}(\%)$ & $\mathrm{t}_{\infty}(\mathrm{h})$ & $\mathrm{m}_{\infty} \mathrm{t}_{\infty}(\% / \mathrm{h})$ \\
\hline $\mathrm{A} 1$ & 97 & 4 & 24.3 \\
$\mathrm{~A} 2$ & 94 & 6 & 15.7 \\
$\mathrm{~A} 3$ & 94 & 11 & 8.5 \\
$\mathrm{~A} 4$ & 86 & 11 & 7.8 \\
$\mathrm{~A} 5$ & 81 & 12 & 6.8 \\
\hline
\end{tabular}

Release kinetics and mechanism of drug release from the non-effervescent floating metronidazole tablets. The results of the various release kinetics for floating metronidazole tablets are represented in Table 6.

The release kinetics of the formulations did not simulate a zero order release model as the plot showed poor linearity with regression values $\left(\mathrm{r}^{2}\right)$ ranging from $0.77-0.87$. This showed that the formulation did not follow the zero order release model, where the amount of drug released is unchanged irrespective of the concentration of the drug remaining in the dosage form. First order release model showed a fair linearity with $\mathrm{r}^{2}$ values ranging from 0.96-0.98. This implied that the quantity of drug released was dependent on the amount of drug left in the formulation. The in vitro release profiles simulated of the metronidazole tablet simulated the Higuchi release model as the plot gave a high linearity with $r^{2}$ values of $0.93-0.98$. This shows that drug release from the matrix tablet were mainly by Higuchi's model which states that the amount of drug released is dependent on the square root of time. ${ }^{10}$

The data obtained were fitted into Korsmeyer and Peppas equation in order to confirm the mechanism of release. ${ }^{11,12}$ The formulation showed poor linearity with $\mathrm{r}^{2}$ values ranging 0.221-0.471. Since the $r^{2}$ values were consistent with Higuchi's model, it was expected that the mechanism of drug release from matrix tablet was diffusion controlled. The release exponent (n) for the floating metronidazole tablets ranged from $0.46-0.53$. All the 
formulations had their release exponent $(\mathrm{n})>0.45$; hence their release mechanism was by Non-Fickian diffusion. Scanning electron micrograph reveals the presence of pores with rough and pitted surface.

Table 6. Release kinetics of metronidazole tablets $(n=3)$ formulated with different amounts of AIG using non-effervescent method.

\begin{tabular}{|c|c|c|c|c|c|c|c|c|}
\hline \multirow{3}{*}{$\begin{array}{l}\text { Models } \\
\text { Formulations }\end{array}$} & \multicolumn{2}{|c|}{ Zero } & \multicolumn{2}{|c|}{ First } & \multicolumn{2}{|c|}{ Higuchi } & \multicolumn{2}{|c|}{ Korsmeyer and Peppas } \\
\hline & 2 & $\mathrm{~K}$ & 2 & $\mathrm{~K}$ & 2 & $\mathrm{~K}$ & 2 & $\mathrm{n}$ \\
\hline & $\mathrm{r}$ & 0 & $\mathrm{r}$ & 1 & $\mathrm{r}$ & $\mathrm{H}$ & $\mathrm{r}$ & \\
\hline A1 & 0.769 & 18.59 & 0.958 & -0.34 & 0.925 & 47.76 & 0.221 & 0.48 \\
\hline $\mathrm{A} 2$ & 0.842 & 12.98 & 0.981 & -0.19 & 0.964 & 38.18 & 0.346 & 0.53 \\
\hline A3 & 0.791 & 6.86 & 0.963 & -0.10 & 0.944 & 26.96 & 0.406 & 0.47 \\
\hline A4 & 0.854 & 6.35 & 0.972 & -0.07 & 0.973 & 24.37 & 0.416 & 0.46 \\
\hline A5 & 0.869 & 6.31 & 0.967 & -0.06 & 0.982 & 24.12 & 0.471 & 0.49 \\
\hline
\end{tabular}

Compatibility studies: Figures 2 and 3 shows the FTIR and DSC spectra. It was observed that there were no significant changes in the peaks and troughs of the spectra. This indicates that the API (metronidazole) was compatible with the other excipients used in the formulation of the tablets.

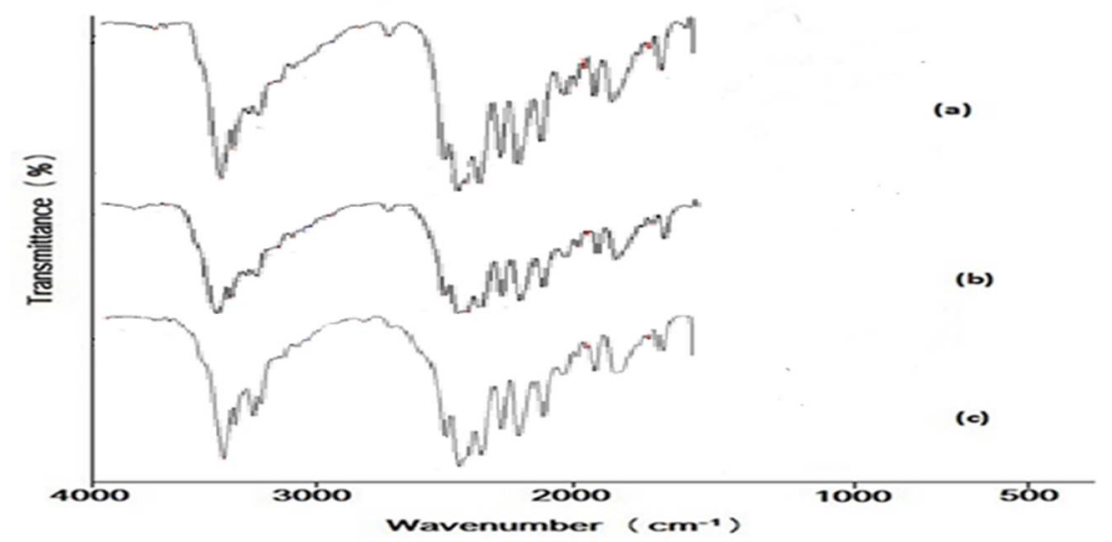

Figure 2. FTIR Spectra of non-effervescent floating tablets. Note: a) Pure metronidazole sample (b) $8 \% \mathrm{w} / \mathrm{w}$ tablet formulation. (c) Physical mixture of metronidazole, neem gum etc.

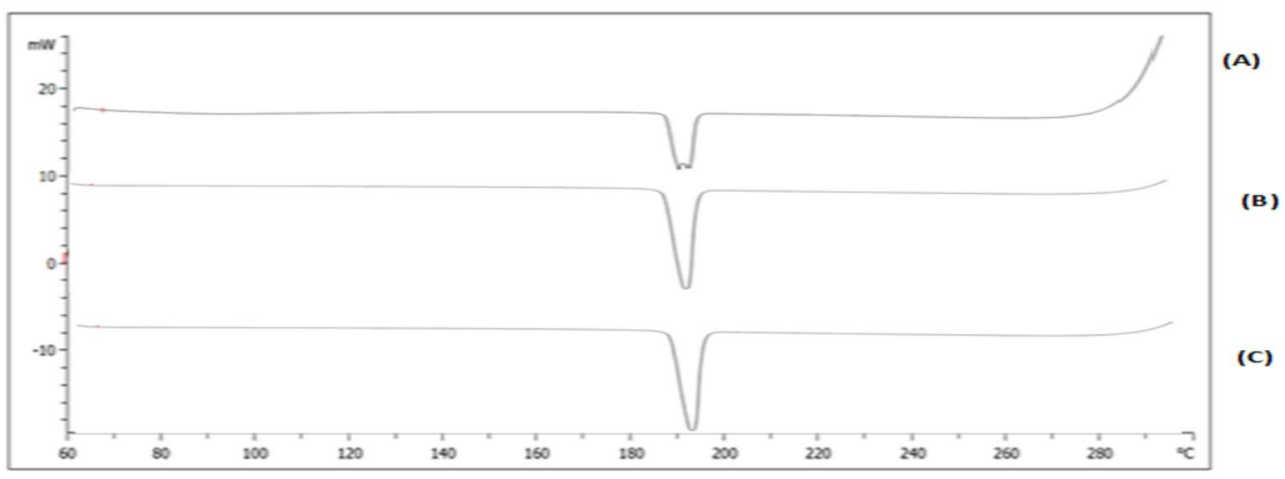

Figure 3. DSC spectra of non-effervescent floating tablets. (A) Optimised tablet formulation (B) Admixture of metronidazole, neem gum, lactose etc. (C) Pure metronidazole sample. 


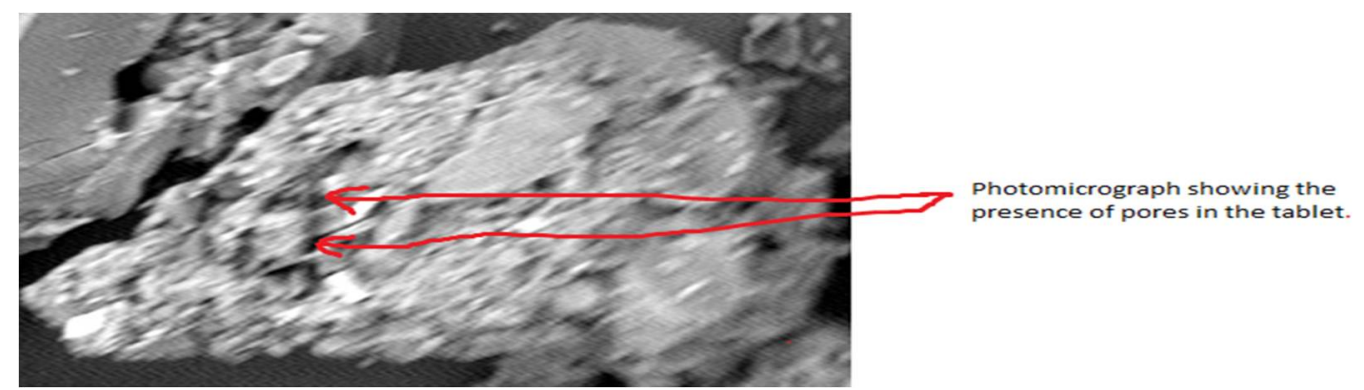

Figure 4. Scanning electron micrograph of non-effervescent floating tablet (x1500).

\section{Conclusion}

Non-effervescent floating metronidazole tablets which floated instantaneously were successfully formulated in this study using A. indica gum in addition with Eudragit ${ }^{\circledR}$ RL100 to prolong gastric retention time and subsequently sustain drug release for up to12 hours.

\section{References}

1. Airemwen, C. O. and Uhumwangho, M. U. 2019. Formulation and Evaluation of effervescent floating matrix tablets of biguanides using Grewia mollis gum. Asian J App sci. 12 (2): 91-98.

2. Rathi, B., Kumar, P.K., Pankaj, K. and Dongre, P. 2017. A review report on important approaches of floating drug delivery system. Asian J. Pharm. 11, 450-455.

3. Airemwen, C. O. and Uhumwangho, M. U. 2016. Formulation and evaluation of floating matrix tablets of metformin using acrylate methacrylate copolymer and Irvingia gabonesis gum. J. Pharm. Allied Sci. 13, 23312343.

4. Orakwe, C., Airemwen, C.O. and Uhumwangho, M.U. 2015. Formulation and evaluation of gastroretentive floating matrix tablets of metronidazole using Khaya Ivorensis gum. Asian J. Pharm. Tech. Inn. 3, 1-9.

5. Airemwen, C. O. and Uhumwangho, M. U. 2017. Gastrofloating drug delivery system- a review. Trop. J. Nat. Prod. Res. 1,105-109.

6. Airemwen, C.O. and Uhumwangho, M.U. 2018. Formulation and evaluation of gastroretentive floating matrix tablets of metronidazole using a novel non-effervescent technique. Saudi J. Med. Pharm. Sci. 4, 257-264.

7. Abayomi, T.O. and Gbenga, A. 2014. Neem gum as a binder in a formulated paracetamol tablet with reference to acacia gum BP. AAPS Pharm. Sci. Tech. 15, 500-507.

8. Carr, R. L. 1965. Evaluating flow properties of solids. Chem. Eng. J. 72, 163-168.

9. Onyekweli, A. O. 2000. Adaptation of Erweka tablet friabilator for tap density measurement. West Afri. J. Pharm. 14, 74-78.
10. Rosa, M., Zia, H. and Rhodes, T. 1994. Dosing and testing in vitro of a bioadhesive and floating drug delivery system for oral application. Int. J. Pharm. 105, 65-70.

11. Higuchi, T. 1963. Mechanism of sustained action medication. Theoretical analysis of rate release of solid drugs dispersed in solid matrices. J. Pharm. Sci. 52, 11451149.

12. Korsmeyer, R.W.; Gurny, R.; Doelker, E. M.; Buri, P. and Peppas, N. A. 1983. Mechanism of solute release from porous hydrophilic polymers. Int. J. Pharm. 15, 25-35.

13. Peppas, N. A. 1985. Analysis of Fickian and non-Fickian drug release from polymers. Pharm. Acta. Helv. 60,110-111.

14. British Pharmacopoeia 2002. London, UK: Her Majesty's Stationery Office: A234.

15. Huanbutta, K., Limmatvapirat, S. and Sungthongjeen, S. 2016. Novel strategy to fabricate floating drug delivery system based on sublimation technique. AAPS Pharm. Sci. Tech. 17, 693-698.

16. Oh, T.O., Kim, J.Y., Ha, J.M., Chi, S.C., Rhee. Y.S. and Park, C.W. 2013. Preparation of highly porous gastroretentive metformin tablets using a sublimation method. Eur. J. Pharm. Biopharm. 83, 460-467.

17. Pawar, V.K., Kansal, S., Garg, G., Awasthi, R., Singodia, D. and Kulkarni, G.T. 2011. Gastroretentive dosage forms: a review with special emphasis on floating drug delivery systems. Drug Deliv. 18, 97-110.

18. Safraz, M. K., Richman, N., Ahmed, S., Ashraf, M. and Moshin, S. 2007. Ethylcellulose-based solid matrix system for sustaining release of naproxen. Pak. J. Bio. Sci. 10, 672688.

19. Raakesh, P. and Ashok, B. 2009. Formulation development and process optimization of theophylline sustained release matrix tablet. Int. J. Pharm. Sci. 2, 30-42.

20. Uhumwangho, M. U. and Okor, R. S. 2006. Modification of drug release from acetaminophen granules by melt granulation technique- consideration of release kinetics. Pak. J. Pharm. Sci. 19, 22-27.

21. Uhumwangho, M. U. and Okor, R. S. 2008. A comparative study of dissolution characteristics of polymeric and wax granulations of theophylline and their tablets. Pak. J. Pharm. Sci. 3, 230-236. 